\title{
Commentary: Slowing of the Time Course of Acidification Decreases the Acid-Sensing Ion Channel 1a Current Amplitude and Modulates Action Potential Firing in Neurons
}

\author{
Matthew William ${ }^{\dagger}$, Victoria Cegielski ${ }^{\dagger}$ and Xiang-Ping Chu* \\ Department of Biomedical Sciences, School of Medicine, University of Missouri-Kansas City, Kansas City, MO, United States \\ Keywords: acid-sensing ion channel 1, slow pH change, action potential, neurodegenerative disease, patch-clamp \\ recording
}

OPEN ACCESS

Edited by:

Marco Canepari

UMR5588 Laboratoire

Interdisciplinaire de Physique

(LIPhy), France

Reviewed by:

Eric Lingueglia,

UMR7275 Institut de Pharmacologie

Moléculaire et Cellulaire

(IPMC), France

Osvaldo D. Uchitel,

University of Buenos Aires, Argentina

*Correspondence:

Xiang-Ping Chu

chux@umkc.edu

†These authors have contributed equally to this work

Specialty section:

This article was submitted to

Cellular Neurophysiology,

a section of the journal

Frontiers in Cellular Neuroscience

Received: 24 May 2021

Accepted: 23 June 2021

Published: 16 July 2021

Citation:

William M, Cegielski V and Chu X-P (2021) Commentary: Slowing of the

Time Course of Acidification

Decreases the Acid-Sensing Ion Channel 1a Current Amplitude and Modulates Action Potential Firing in Neurons.

Front. Cell. Neurosci. 15:714204. doi: 10.3389/fncel.2021.714204

\section{A Commentary on}

Slowing of the Time Course of Acidification Decreases the Acid-Sensing Ion Channel 1a Current Amplitude and Modulates Action Potential Firing in Neurons

by Alijevic, O., Bignucolo, O., Hichri, E., Peng, Z., Kucera, J. P., and Kellenberger, S. (2020). Front. Cell. Neurosci. 14:41. doi: 10.3389/fncel.2020.00041

\section{INTRODUCTION}

Multiple disorders are associated with a decrease in cerebral extracellular $\mathrm{pH}$, including brain ischemia, seizures, and neurodegenerative diseases like multiple sclerosis (Vergo et al., 2011; Chu and Xiong, 2012; Friese et al., 2014; Leng et al., 2014; Tóth et al., 2020). The increase in concentration of protons that this acidic state leads to is capable of activating acid-sensing ion channels (ASICs), which are widely expressed in the nervous system (Price et al., 2014; Storozhuka et al., 2021). The most predominant of these channels in the brain is the ASICla subtype (Waldmann et al., 1997; Chu et al., 2014; Gründer and Pusch, 2015). Activation of ASIC1a is capable of inducing membrane depolarization in the neuron, increasing the probability of an action potential (AP) spike (Baron et al., 2002; Jiang et al., 2009; Wemmie et al., 2013; Boscardin et al., 2016). Empirically, it was well-documented how ASIC1a responds to rapid drops in pH by inducing membrane depolarization (Waldmann et al., 1997; Krishtal, 2015). Despite this, multiple conditions instead involve a slow ( $>10 \mathrm{~s}$ ) decrease in $\mathrm{pH}$, such as ischemia, inflammation, and seizures (Chesler, 2003). Furthermore, due to the $\mathrm{pH}$ dependence of the desensitization of ASICs including ASIC1a, the amplitudes of the peak current depend on the speed of acidification. For example, if the rise in proton concentration is significantly slower than desensitization, peak currents will be reduced (Gründer and Pusch, 2015). In addition, studies on the effect of ASIC activation on neuron excitability have also shown that transient depolarization induced by small $\mathrm{pH}$ drops (e.g., pH6.6) can trigger an initial AP as well as spontaneous AP trains in neurons, whereas lower $\mathrm{pH}$ values reduced AP firing and can only produce an initial AP at pH5.0. This is in good agreement with inactivation of voltage-gated sodium channels (Baron et al., 2002; Vukicevic and Kellenberger, 2004). While it is known that ASIC1a plays a critical role in reacting to such events, the extent of its response to these conditions has been relatively unknown. Recently, a team from Kellenberger's laboratory uncovered ASIC1a's response to slow changes in $\mathrm{pH}$ (Alijevic et al., 2020). They reported that ASIC1a leads to differing levels of neuronal activity with different rates of $\mathrm{pH}$ 
change for the same $\mathrm{pH}$ of activation. They provide a welldocumented quantitative description of these effects, including how amplitude and speed of the $\mathrm{pH}$ change affect AP firing in cortical neurons, as well as the development of a Hodgkin-Huxley $(\mathrm{HH})$-based model of ASICla function. This demonstrates that the responses of ASIC1a to acidosis are dependent on the amount of time it takes for that change to be reached and that slow $\mathrm{pH}$ changes (between 4 and $10 \mathrm{~s}$ ) also affect neuronal activation.

\section{INTERMEDIATELY SLOW PH CHANGE LEADS TO INCREASED AP DURATION}

A Swiss study from Frontiers in Cellular Neuroscience (Alijevic et al., 2020) recently added to literature regarding the most prevalent ASIC subtype in the brain, ASIC1a. Previous studies that focused on ASIC1a reported fast $\mathrm{pH}$ changes (fall time $<4 \mathrm{~s}$ ) which induced membrane depolarization of this channel (Jiang et al., 2009; Kellenberger and Schild, 2015). Alijevic and other authors from Kellenberger's laboratory filled a gap in ASIC1a knowledge by researching how intermediately slow acidification (fall time between 4 and $10 \mathrm{~s}$ periods of $\mathrm{pH}$ changes) and slow acidification (fall time $>10 \mathrm{~s}$ periods of $\mathrm{pH}$ changes) impacted the amplitudes of ASIC1a current and duration of the current. To do so, they recorded the ASIC1a currents in Chinese hamster ovary $(\mathrm{CHO})$ cells expressing the ASICla protein and developed a kinetic model of this current. This kinetic model was then integrated into a $\mathrm{HH}$-based neuronal model. The $\mathrm{HH}$ approach was chosen over a Markovian model in order to accommodate a greater number of parameters. These parameters included two types of kinetics observed in ASIC1a: rapid and slow transitions. In the experiment, outside-out patch recordings were used to test rapid transitions including open channel desensitization and deactivation, whereas slower processes like steady-state desensitization and recovery from desensitization were measured using whole-cell patch configuration. Using the HH model, they found that intermediately slow acidification of ASIC1a, falling in the 4-10 s time range called intermediately slow $\mathrm{pH}$ ramps, decreased ASIC1a current amplitudes, but increased neuronal action potentials (APs) with this protocol. This intermediately slow $\mathrm{pH}$ ramp (e.g., $5 \mathrm{~s}$ ) produced decreased ASIC1a current amplitudes by causing APs to fire later and with higher number. The enhanced numbers of APs and firing time are likely due to increased acceleration of the kinetics of the inactivation gate of voltage-gated sodium channels (Vilin et al., 2012). In addition to this, the $\mathrm{m}$-gate of voltage-gated sodium channel requires a negative shift in its voltage dependence, and the h-gate of voltagegated sodium channel requires a positive shift in its voltage dependence to experience enhanced numbers of APs and firing time. They further examined the neuronal activation in neurons from wild-type, ASIC1a and ASIC2 knockout mice. They found that $\mathrm{pH}$ drop did not produce any APs regardless of acidification time in cortical neurons from ASIC1a knockout mice. However, APs recorded in neurons from wild-type and ASIC2 knockout mice were affected by slower $\mathrm{pH}$ ramps. The results suggest that the presence and functionality of ASIC1a plays a critical role in producing APs in cortical neurons. Furthermore, slow acidification that timed $>10 \mathrm{~s}$ did not generate any ASIC currents regardless of neuron type in most of the experiments.

\section{DISCUSSION}

This new study from Kellenberger's laboratory significantly adds to the ASIC field by detailing how ASIC1a reacts to $\mathrm{pH}$ changes that last longer than $4 \mathrm{~s}$ (Alijevic et al., 2020). Because they analyze long-term $\mathrm{pH}$ changes in ASICs, as opposed to most other ASIC studies which utilize rapid $\mathrm{pH}$ change in milliseconds range (Xiong et al., 2004; Jiang et al., 2009, 2017), future studies should be conducted to confirm these findings and expand on their significance. For instance, they found that intermediate acidification of ASIC1a increases neuronal activation and decreases the ASIC1a current amplitude, but the clinical manifestations of this finding are still unknown. Future studies should be conducted to identify the effects of this increased AP duration, and how it contributes to the pathology of diseases that involve intermediately slow acidification. Additionally, the study has shown that slow acidification over $10 \mathrm{~s}$ leads to virtually no AP generation. Although diseases states such as ischemia involve slow acidification, ASIC1a still plays a critical role in such conditions (Xiong et al., 2004). In ischemiainduced acidosis, ASIC1a is permeable to calcium ions, leading to death of the neuron (Xiong et al., 2004; Chu and Xiong, 2012); activation of ASIC1a also can trigger necroptosis by $\mathrm{Ca}^{2+}$-independent mechanisms (Wang et al., 2015). While many studies have focused on the role of ASICs in neurons, not many have investigated the role that ASICs play in other cell types in the brain. For instance, ASIC1 has shown to be expressed in highgrade gliomas and was involved in tumor growth (Berdiev et al., 2003; Sheng et al., 2021). Future studies may examine how ASIC1 activated by slow $\mathrm{pH}$ changes in high-grade gliomas can affect the tumor growth. Thus, targeting ASICla becomes a promising therapeutic strategy for neurodegenerative diseases and brain tumors (Chu and Xiong, 2012; Chu et al., 2014).

\section{AUTHOR CONTRIBUTIONS}

All authors listed have made a substantial, direct and intellectual contribution to the work, and approved it for publication.

\section{FUNDING}

The work was supported by grant from American Heart Association (19AIREA34470007) to X-PC.

\section{ACKNOWLEDGMENTS}

We would like to thank the University of Missouri-Kansas City School of Medicine student research program for their support of MW and VC's professional studies. 


\section{REFERENCES}

Alijevic, O., Bignucolo, O., Hichri, E., Peng, Z., Kucera, J. P., and Kellenberger, S. (2020). Slowing of the time course of acidification decreases the acid-sensing ion channel la current amplitude and modulates action potential firing in neurons. Front. Cell. Neurosci. 14:41. doi: 10.3389/fncel.2020.00041

Baron, A., Waldmann, R., and Lazdunski, M. (2002). ASIC-like, protonactivated currents in rat hippocampal neurons. J. Physiol. 539, 485-494. doi: $10.1113 /$ jphysiol.2001.014837

Berdiev, B. K., Xia, J., McLean, L. A., Markert, J. M., Gillespie, G. Y., Mapstone, T. B., et al. (2003). Acid-sensing ion channels in malignant gliomas. J. Biol. Chem. 278, 15023-15034. doi: 10.1074/jbc.M300991200

Boscardin, E., Alijevic, O., Hummler, E., Frateschi, S., and Kellenberger, S. (2016). The function and regulation of acid-sensing ion channels (ASICs) and the epithelial $\mathrm{Na}(+)$ channel (ENaC): IUPHAR Review 19. Br. J. Pharmacol. 173, 2671-2701. doi: 10.1111/bph.13533

Chesler, M. (2003). Regulation and modulation of $\mathrm{pH}$ in the brain. Physiol. Rev. 83, 1183-1221. doi: 10.1152/physrev.00010.2003

Chu, X.-P., Grasing, K. A., and Wang, J. Q. (2014). Acid-sensing ion channels contribute to neurotoxicity. Transl. Stroke Res. 5, 69-78. doi: 10.1007/s12975-013-0305-y

Chu, X.-P., and Xiong, Z.-G. (2012). Physiological and pathological functions of acid-sensing ion channels in the central nervous system. Curr. Drug Targets 13, 263-271. doi: 10.2174/138945012799201685

Friese, M. A., Schattling, B., and Fugger, L. (2014). Mechanisms of neurodegeneration and axonal dysfunction in multiple sclerosis. Nat. Rev. Neurol. 10, 225-238. doi: 10.1038/nrneurol.2014.37

Gründer, S., and Pusch, M. (2015). Biophysical properties of acidsensing ion channels (ASICs). Neuropharmacology 94, 9-18. doi: 10.1016/j.neuropharm.2014.12.016

Jiang, N., Wu, J., Leng, T., Yang, T., Zhou, Y., Jiang, Q., et al. (2017). Region specific contribution of ASIC2 to acidosis-and ischemia-induced neuronal injury. J. Cereb. Blood Flow Metab. 37, 528-540. doi: 10.1177/0271678X16630558

Jiang, Q., Li, M. H., Papasian, C. J., Branigan, D., Xiong, Z. G., Wang, J. Q., et al. (2009). Characterization of acid-sensing ion channels in medium spiny neurons of mouse striatum. Neuroscience 162, 55-66. doi: 10.1016/j.neuroscience.2009.04.029

Kellenberger, S., and Schild, L. (2015). International union of basic and clinical pharmacology. XCI. structure, function, and pharmacology of acid-sensing ion channels and the epithelial Na+ channel. Pharmacol. Rev. 67, 1-35. doi: 10.1124/pr.114.009225

Krishtal, O. (2015). Receptor for protons: First observations on acid sensing ion channels. Neuropharmacology 94, 4-8. doi: 10.1016/j.neuropharm.2014. 12.014

Leng, T., Shi, Y., Xiong, Z. G., and Sun, D. (2014). Proton-sensitive cation channels and ion exchangers in ischemic brain injury: new therapeutic targets for stroke? Prog. Neurobiol. 115, 189-209. doi: 10.1016/j.pneurobio.2013.12.008
Price, M. P., Gong, H., Parsons, M. G., Kundert, J. R., Reznikov, L. R., Bernardinelli, L., et al. (2014). Localization and behaviors in null mice suggest that ASIC1 and ASIC2 modulate responses to aversive stimuli. Genes Brain Behav. 13, 179-194. doi: $10.1111 / \mathrm{gbb} .12108$

Sheng, Y., Wu, B., Leng, T., Zhu, L., and Xiong, Z. (2021). Acid-sensing ion channel 1 (ASIC1) mediates weak acid-induced migration of human malignant glioma cells. Am. J. Cancer Res. 11, 997-1008.

Storozhuka, M., Cherninskyia, A., Maximyuka, O., Isaeva, D., and Krishtala, O. (2021). Acid-sensing ion channels: focus on physiological and some pathological roles in the brain. Curr. Neuropharmacol. doi: 10.2174/1570159X19666210125151824. [Epub ahead of print].

Tóth, O. M., Menyhárt, Á., Frank, R., Hantosi, D., Farkas, E., and Bari, F. (2020). Tissue acidosis associated with ischemic stroke to guide neuroprotective drug delivery. Biology 9:460. doi: 10.3390/biology9120460

Vergo, S., Craner, M. J., Etzensperger, R., Attfield, K., Friese, M. A., Newcombe, J., et al. (2011). Acid-sensing ion channel 1 is involved in both axonal injury and demyelination in multiple sclerosis and its animal model. Brain 134, 571-584. doi: 10.1093/brain/awq337

Vilin, Y. Y., Peters, C. H., and Ruben, P. C. (2012). Acidosis differentially modulates inactivation in Nav1.2, Nav1.4, and Nav1.5 channels. Front. Pharmacol. 3:109. doi: 10.3389/fphar.2012.00109

Vukicevic, M., and Kellenberger, S. (2004). Modulatory effects of acid-sensing ion channels on action potential generation in hippocampal neurons. Am. J. Physiol. Cell Physiol. 287, C682-C690. doi: 10.1152/ajpcell.00127.2004

Waldmann, R., Champigny, G., Bassilana, F., Heurteaux, C., and Lazdunski, M. (1997). A proton-gated cation channel involved in acid-sensing. Nature 386, 173-177. doi: 10.1038/386173a0

Wang, Y. Z., Wang, J. J., Huang, Y., Liu, F., Zeng, W. Z., Li, Y., et al. (2015). Tissue acidosis induces neuronal necroptosis via ASICla channel independent of its ionic conduction. Elife 4:e05682. doi: 10.7554/eLife.05682

Wemmie, J. A., Taugher, R. J., and Kreple, C. J. (2013). Acid-sensing ion channels in pain and disease. Nat. Rev. Neurosci. 14, 461-471. doi: 10.1038/nrn3529

Xiong, Z. G., Zhu, X. M., Chu, X. P., Minami, M., Hey, J., Wei, W. L., et al. (2004). Neuroprotection in ischemia: blocking calcium-permeable acid-sensing ion channels. Cell 118, 687-698. doi: 10.1016/j.cell.2004.08.026

Conflict of Interest: The authors declare that the research was conducted in the absence of any commercial or financial relationships that could be construed as a potential conflict of interest.

Copyright (c) 2021 William, Cegielski and Chu. This is an open-access article distributed under the terms of the Creative Commons Attribution License (CC BY). The use, distribution or reproduction in other forums is permitted, provided the original author(s) and the copyright owner(s) are credited and that the original publication in this journal is cited, in accordance with accepted academic practice. No use, distribution or reproduction is permitted which does not comply with these terms. 